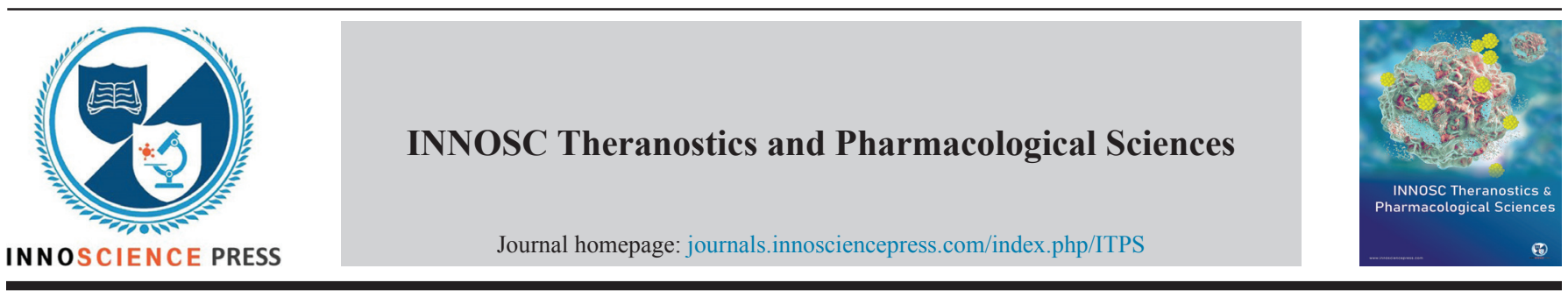

RESEARCH ARTICLE

\title{
In Silico Study of Curcumin and Folic Acid as Potent Inhibitors of Human Transmembrane Protease Serine 2 in the Treatment of COVID-19
}

\author{
Noboru Motohashi ${ }^{1}$, Anuradha Vanam², Rao Gollapudi ${ }^{3 *}$ \\ ${ }^{1}$ Meiji Pharmaceutical University, Noshio, Kiyose-shi, Tokyo, Japan \\ ${ }^{2}$ Sri Venkateswara University, Tirupathi, Andhra Pradesh, India \\ ${ }^{3}$ University of Kansas, Lawrence, KS 66045, U.S.A \\ *Corresponding Author: Rao Gollapudi, Email: gollapudirao@ku.edu, Tel: (785) 3938872
}

Received: July 27, 2020; Accepted: September 29, 2020; Published: October 16, 2020 DOI: 10.36922/itps.v3i2.935

Copyright: (C) 2020 Motohashi, et al. This is an open-access article distributed under the terms of the Creative Commons AttributionNonCommercial 4.0 International 4.0 (CC BY-NC 4.0), which permits all non-commercial use, distribution, and reproduction in any medium, provided the original work is properly cited.

\begin{abstract}
:
Background. Human transmembrane protease 2 (TMPRSS2) protein is essential for priming spike protein of severe acute respiratory syndrome coronavirus 2 (SARS-CoV-2) in association with human angiotensin-converting enzyme 2 (ACE2) surface receptor to facilitate viral invasion into host human cell through ACE2 receptor. Impeding TMPRSS2 protein activity is currently a preferred choice of the treatment of coronavirus disease 2019 (COVID-19) which is caused by SARS-CoV-2. Curcumin and folic acid are potential candidates for inhibiting TMPRSS2.

Objective. The present study aimed to demonstrate the inhibitory activities of curcumin and folic acid, along with known human serine protease inhibitors such as nafamostat and camostat, on TMPRSS2.

Methods. Curcumin and folic acid, along with nafamostat and camostat, were docked on a modeled human TMPRSS2 protein 3D structure. Nafamostat and curcumin interactions with targeted TMPRSS2 protein were identical whereas camostat and folic acid displayed similar interactions.

Results. The hydrogen bond (H-bond) energies of docked curcumin, folic acid, nafamostat, and camostat were $-19.86 \mathrm{~kJ} / \mathrm{mol},-17.63 \mathrm{~kJ} / \mathrm{mol},-10.53 \mathrm{~kJ} / \mathrm{mol}$, and $-14.41 \mathrm{~kJ} / \mathrm{mol}$, respectively. Higher H-bond energies could strengthen protein-ligand interactions. Our results showed binding site similarities between curcumin and nafamostat as well as folic acid and camostat.

Conclusion. The current in silico simulation suggested that curcumin and folic acid displayed binding poses with TMPRSS2 which are similar to nafamostat and camostat. Therefore, curcumin and folic acid could emerge as potential drug candidates to control COVID-19.
\end{abstract}

Keywords: Human transmembrane protease 2, Angiotensin-converting enzyme 2, Spike protein, Severe acute respiratory syndrome coronavirus 2, Curcumin, Folic acid

\section{Background}

On March 11, 2020, the World Health Organization announced the outbreak of coronavirus disease 2019 (COVID-19) as a pandemic. COVID-19 outbreak was first known to be triggered in Wuhan city, Hubei Province of China, by a virus known as severe acute respiratory syndrome coronavirus 2 (SARS-CoV-2). Severe pneumonia, respiratory failure, acute respiratory distress syndrome, and cardiac injury with fatal outcomes are the symptoms of COVID-19. The COVID-19 pandemic affected over 4.3 million of global population, including over 290,000 deaths, and distressed the global 
economy $[1,2]$. The mortality rate in the world is rising quickly. The rapid spread of SARS-CoV-2 infection in several parts of China and other countries was caused by the environmental exposure and person-to-person transmission [3]. However, the diffusion dynamics and total range of clinical illnesses were not completely evaluated.

The mature form of SARS-CoV-2 is composed of four structural proteins, that is, envelope, membrane, nucleocapsid, and spike protein. Envelop and membrane proteins assist in viral assembly, and the nucleocapsid protein is required for RNA synthesis. The spike protein facilitates the entry of virus into host human cell after the activation by human transmembrane protease 2 TMPRSS2. SARS-CoV-2 spike protein, furin, angiotensinconverting enzyme 2 (ACE2), TMPRSS2, and importin $\alpha / \beta$ are involved in nuclear transport and designated as prime targets for COVID-19 drug discovery. SARS-CoV-2 enters the host cell through ACE2 surface receptor by getting attached to viral spike protein located on the viral envelope. TMPRSS2 protein is a single-pass type II membrane protein of the peptidase family S1 and coded by gene 21q22.3 located on human chromosome 21 . The host's TMPRSS2 protein plays a key role in priming viral spike protein whereas host's ACE2 receptor instigates viral entry into host cell $[2,4]$.

The inhibitors of TMPRSS2 protein prevent virus incursion into the host cell. It has been reported that TMPRSS2 played an important role in the progression of SARS, Middle East respiratory syndrome (MERS), and some influenza infections in a similar manner as SARS-CoV-2. [2,4-10]. The increased viral genomic mutations result in multiple physiognomies of protein structure, which represent a challenge to counter viral resistance to drugs. Thus, targeting host protein, rather than virus or its proteins, to prevent viral infection is generally preferred for therapeutic purposes [11,12]. Besides, the previous study showed that TMPRSS2deficient mouse did not suffer from any apparent complications, corroborating that manipulation of TMPRSS2 protein is effective to control COVID-19 [13]. Camostat and nafamostat, which are the inhibitors of TMPRSS2, are the approved drugs used to treat other viral infections, and their efficacy in the treatment of SARS-CoV-2 infection is presently evaluated in clinical trials [11-13].
At present, effective antiviral therapy is not available for treating COVID-19 patients. However, the present treatment encompasses a combination of antiviral agents, antibiotics, and anti-inflammatory agents. Curcumin is known for its anti-inflammatory, antioxidant, antitumor, and pleiotropic activities [14]. Curcumin is effective against adenovirus, hepatitis virus, human immunodeficiency virus, human papilloma virus, herpes simplex virus 2, viruses, influenza virus, and Zika virus [14,15]. The antiviral mechanisms of curcumin include the suppression of cellular signaling pathways and direct intrusion of viral replication machinery essential for viral growth $[14,15]$. In a previous docking study, the dual binding affinity of curcumin with viral spike protein and ACE2 was verified [16]. Curcumin attachment with active sites of viral spike protein and ACE2 receptor evidently showed that curcumin could emerge as a valuable inhibitory agent to prevent the entry of SARS-CoV-2 protein [16]. A previous study demonstrated that furin cleaved processor proteins in specific patterns to yield biologically active mature proteins [17]. The inhibition of furin activity by folic acid affected the structure of SARS-CoV-2 spike protein and thereby thwarted the protein's proteolytic cleavage ability [18]. Hence, curcumin and folic acid were chosen for our study to evaluate their efficacy in inhibiting human TMPRSS2. In silico docking study was carried out to examine the binding interactions ofTMPRSS2 with curcumin and folic acid, along with known inhibitors such as nafamostat and camostat (Figure 1).

\section{Methods}

\subsection{Protein preparation (homology modeling of the TMPRSS2 protein)}

In drug discovery process, homology modeling makes use of experimental protein structures ("templates") to build receptor proteins. Homology (or comparative) modeling is so far a highly accurate method to generate reliable three-dimensional (3D) protein structure models. SWISS-MODEL was a structural bioinformatics web server dedicated to homology modeling to predict protein 3D structures $[19,20]$. At present, the X-ray structure of human TMPRSS2 protein is not available. As a result, TMPRSS2 protein model was built on 
SWISS-MODEL platform using FASTA sequence retrieved from Uniprot (UniProtKB-015393) and human serine protease hepsin (PDB ID: 5CE1) as template. The 3D structure of TMPRSS2 protein was generated through modeling by submitting TMPRSS2 FASTA sequence into SWISS-MODEL Workspace in automated mode [21-24]. The hepsin protein sequence was chosen as target protein and query sequence as this sequence exhibits the highest resemblance to the query sequence, which was expended to develop an acceptable model of TMPRSS2 protein. Global and local quality estimate assessments regarding TMPRSS2 model template alignment with hepsin are disclosed in Figure 2.

\subsection{Validation of TMPRSS2 modeled protein}

The quality of TMPRSS2 protein model was validated by Ramachandran plot using RAMPAGE [23] and DeepView (version 4.10) by superimposing TMPRSS2 protein model along with hespin [24]. There are $92.7 \%$ residues in favored region, $6.7 \%$ residues in allowed region, and $0.6 \%$ residues in the outlier region (Figure 3). These parameters of protein structure suggested that TMPRSS2 was stable, suitable, and of superior quality for docking.

\subsection{Preparation of ligand}

The dimensional structures of curcumin, folic acid, nafamostat, and camostat were initially<smiles>COc1cc(/C=C/C(=O)CC(=O)/C=C/c2ccc(O)c(OC)c2)ccc1O</smiles>

Curcumin<smiles>N=C(N)Nc1ccc(C(=O)Oc2ccc3cc(C(=N)N)ccc3c2)cc1</smiles><smiles>Nc1nc2ncc(CNc3ccc(C(=O)NC(CCC(=O)O)C(=O)O)cc3)nc2c(=O)[nH]1</smiles>

Folic Acid<smiles>CN(C)C(=O)COC(=O)CC1=CC=C(OC(=O)c2ccc(NC(=N)N)cc2)CC1</smiles>

Figure 1. Chemical structures of curcumin, folic acid, nafamostat, and camostat

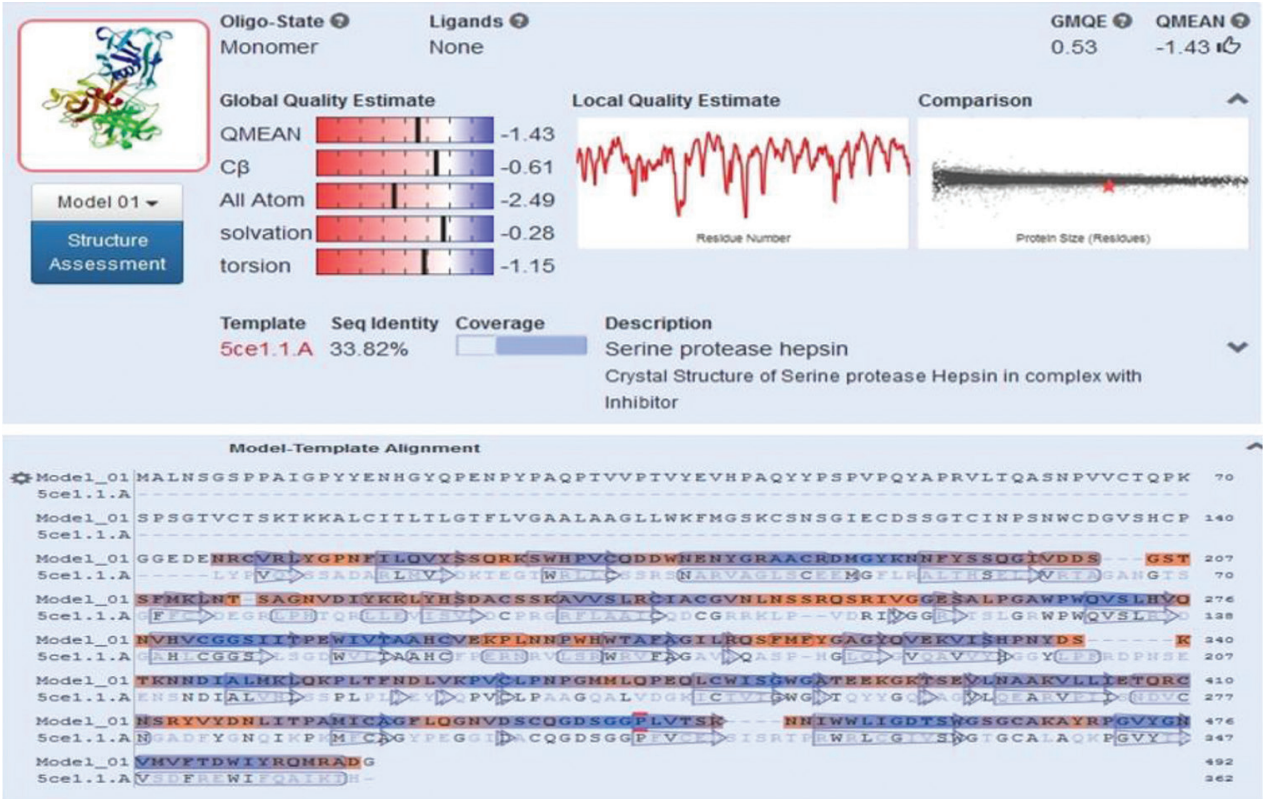

Figure 2. Global and local quality estimate assessments regarding TMPRSS2 model template alignment with hepsin 


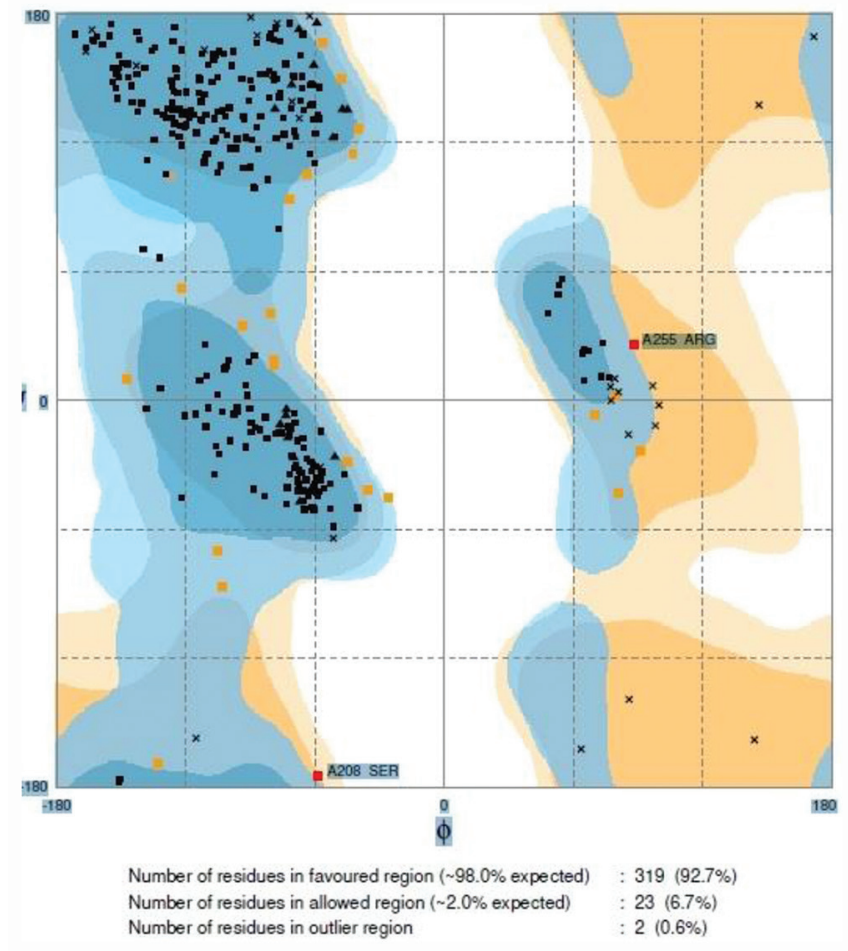

Figure 3. Ramachandran plot of TMPRSS2 model (modeled TMPRSS2) protein

drawn using ChemDraw software (ChemDraw 10.1). Later, the structures were converted to three dimensional Protein Data Bank (PDB) format with the help of Chem3D software (Chem3D 18.1). The molecular geometry optimization of ligands was obtained with energy minimization using molecular mechanics (MM2) force field and saved in PDB format. The missing bond orders, charges, bonds, and hybridization states of these structures were assigned using Molegro Virtual Docker (MVD) software [25].

\subsection{Protein preparation}

The modeled TMPRSS2 protein was prepared for docking study by allocating bonds, bond orders, hybridization, and charges using MVD software [25].

\subsection{Validation of docking protocol}

Before obtaining the crystal structure of TMPRSS2, the docking protocol was validated by choosing X-ray crystallographic structure of hespin. The cocrystalized protein and 50K900 ligand (2-[6-(1-hydroxycyclohexyl)pyridine-2-y1]-1-Hindole-5-carboximidamide) complex was retrieved from Protein Data Bank. Since hespin structure closely resembles that of TMPRSS2 protein, it was selected for modeling TMPRSS2 protein. Consequently, the docking protocol was validated by redocking the extracted ligand from X-ray crystallographic structure of hespin and comparing the interactions between ligand and targeted protein. The X-ray crystallographic interactions between ligand and hespin closely resembled the docked complexes, as shown in Figure 4.

\section{Results and discussion}

\subsection{Scores}

MolDock scores were calculated using piecewise linear potential scoring method and the scores were suitable to protein-ligand structures and binding data scoring functions. In the docking process, MolDock simplex evolution search algorithm with a grid resolution $0.30 \AA$ was used [26]. The greater volume cavity created by MVD was preferred for the binding site. The ligands were docked with TMPRSS2 protein model and the finest poses were selected based on the dock scores [27]. The values for scoring functions and energies were calculated in Dock score, Rerank score, and MolDock score [28]. The Dock scores for curcumin, nafamostat, folic acid, and camostat are $-231.68 \mathrm{~kJ} / \mathrm{mol},-217.68 \mathrm{~kJ} / \mathrm{mol},-231.87 \mathrm{~kJ} / \mathrm{mol}$, and $-235.92 \mathrm{~kJ} / \mathrm{mol}$, respectively. The Rerank scores for curcumin, nafamostat, folic acid, and camostat are $-64.51 \mathrm{~kJ} / \mathrm{mol},-55.17 \mathrm{~kJ} / \mathrm{mol},-62.80 \mathrm{~kJ} / \mathrm{mol}$, and $-76.56 \mathrm{~kJ} / \mathrm{mol}$, respectively. The MolDock scores for curcumin, nafamostat, folic acid, and camostat are $-95.76 \mathrm{~kJ} / \mathrm{mol},-85.10 \mathrm{~kJ} / \mathrm{mol}$, $-106.51 \mathrm{~kJ} / \mathrm{mol}$, and $-107.06 \mathrm{~kJ} / \mathrm{mol}$, respectively. All the ligands bonded with amino acid Asn-451 of TMPRSS2.

Based on the findings, we found that TMPRSS2 protein is a highly effective target for the treatment of COVID-19 caused by SARS-CoV-2 [29]. As TMPRSS2 plays an important function in the entry of SARS-CoV-2, MERS-CoV-2, and some influenza viruses into the host cell $[5,6,8,10]$, targeting TMPRSS2 will become a more direct approach to control the infectious diseases caused by these viruses.

\subsection{Analysis}

The scores for all the residues clustered in the cavity of TMPRSS2 evidently suggest that curcumin, folic acid, nafamostat, and camostat dock flawlessly on the 
active site in the hydrophobic cavity of TMPRSS2 protein model. Curcumin and nafamostat displayed identical active interactions with Ser-250, Gln-253, Ser-448, Trp-453 (hydrophobic interactions), and Asn-451 (hydrogen bonds, H-bonds) located on the active site of TMPRSS2 model protein. Folic acid and camostat docked perfectly on the active site of TMPRSS2 protein model and displayed intricately identical active interactions with Ser-250, Trp-267, and Asn-450 (hydrophobic interactions) as well as Arg-252, Ser-254, and Asn-451 (H-bonds). Nonetheless, camostat displayed three additional interactions with Asn-247, Gln-253, and Ala-266 amino acid residues (H-bonds) of TMPRSS2 protein model. H-bonds strengthen numerous cellular functions by enabling molecular interactions, and they are considered the mediators of receptor-ligand

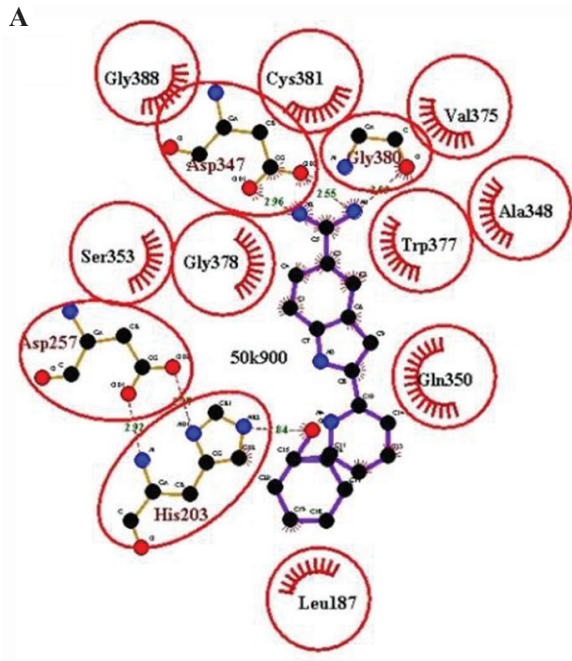

X-ray Crystal Structure of 5 ce 1 and $50 \mathrm{k} 900$ interactions [30]. The average H-bond energies of curcumin, nafamostat, folic acid, and camostat are $-9.86 \mathrm{~kJ} / \mathrm{mol},-10.53 \mathrm{~kJ} / \mathrm{mol},-17.63 \mathrm{~kJ} /$ $\mathrm{mol}$, and $-14.41 \mathrm{~kJ} / \mathrm{mol}$, respectively. Besides, all the docked ligands form H-bonds with Asn-451 of TMPRSS2 suggesting the prominence of Asn-451 in stabilizing protein-ligand complex. The protein-ligand interaction contributed to the inhibition of TMPRSS2 activity. The graphics displaying interactions between protein and ligands (Figure 5) were created using LIGPLOT (http:// www.ebi.ac.uk/thornton-srv/software/LIGPLOT/). The docking positions of curcumin/nafamostat and folic acid/camostat on human TMPRSS2 are displayed in Figure 6.

TMPRSS2 expression distinctively diminished cellular epithelial sodium channel protein

B

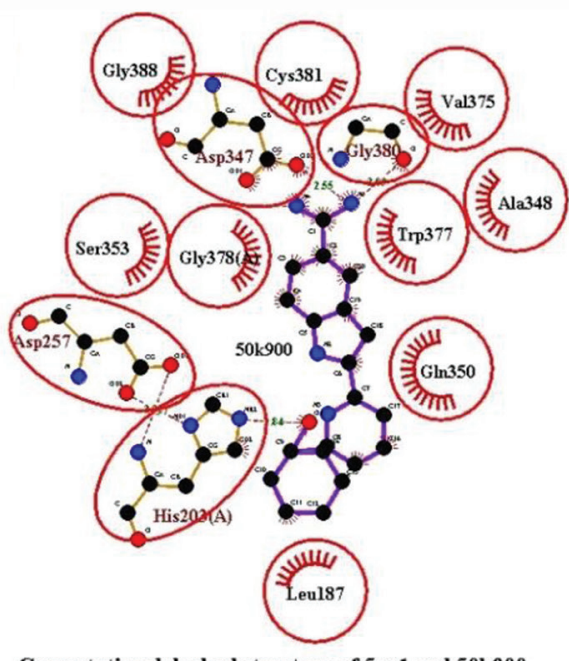

Computational docked structure of $5 c e 1$ and $50 \mathrm{k} 900$

Figure 4. X-ray crystallographic interactions between ligand and hespin. (A) Interactions between X-ray structures of ligand 50K900 and hespin. (B) Interactions between computational docked structures of ligand $50 \mathrm{~K} 900$ and hespin

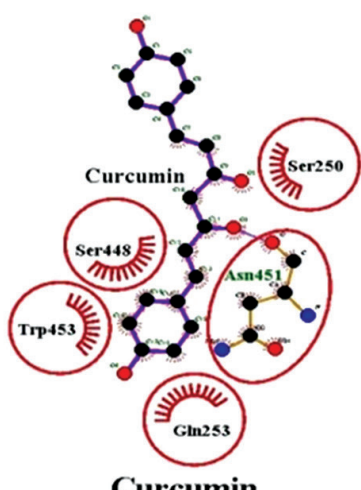

Curcumin

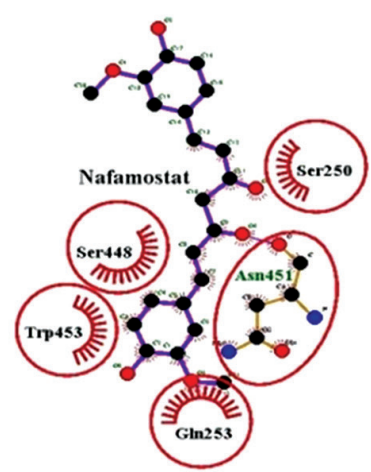

Nafamostat

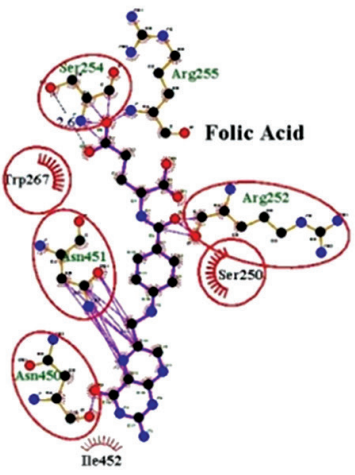

Folic Acid

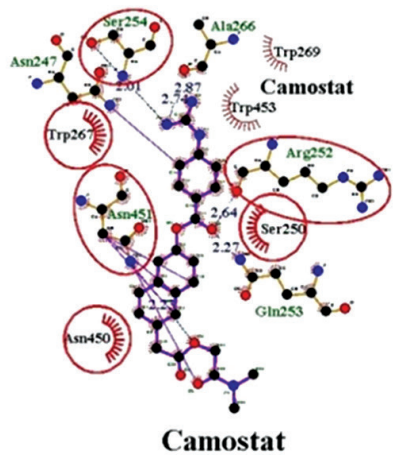

Camostat

Figure 5. TMPRSS2-ligand interactions of curcumin, nafamostat, folic acid, and camostat 


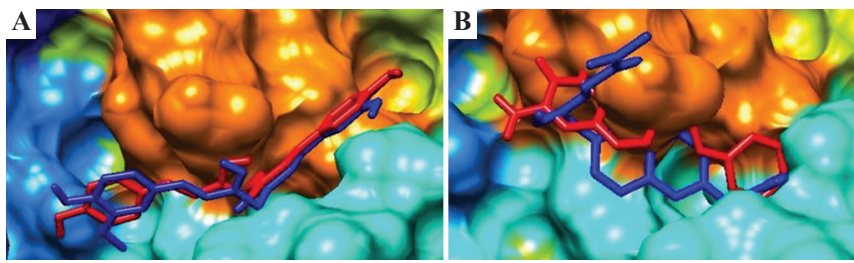

Figure 6. Docking positions of ligands on human TMPRSS2. (A) Curcumin (red) and nafamostat (blue). (B) Folic acid (red) and camostat (blue).

levels in cystic fibrosis lungs [31]. As shown in TMPRSS2-deficient mice, however, TMPRSS2 is not associated with a vital function, probably due to functional redundancy of the type II transmembrane serine proteases [32]. This indicates that TMPRSS2 inhibition during viral infections could be a harmless approach. Although TMPRSS2 inhibition had never been thoroughly evaluated, drugs such as nafamostat and camostat were employed to inhibit TMPRSS2. Recently, nafamostat and camostat have been recommended to be used in the emergency treatment of COVID-19 [12,13,33,34]. On the other hand, in silico docking study revealed that folic acid inhibited furin enzyme, which cleaves multiple precursor proteins to yield biologically active proteins, in the initial stages of respiratory disease instigated by COVID-19 and accelerated the activation of coronavirus by sequence-specific cleavage of spike protein $[16,17,35]$.

Our results suggest the key roles of hydrophobic forces and H-bonds in stabilizing the TMPRSS2ligand complexes leading to the inactivation of TMPRSS2. Curcumin and folic acid also showed comparable affinity to the known TMPRSS2 inhibitors such as nafamostat and camostat in the present study. Assuming that curcumin and folic acid have TMPRSS2 binding alignments that are akin to the nafamostat and camostat, we can presume that curcumin and folic acid display similar inhibitory activities similar to these known ligands. The median molecular interaction energy of the four ligands allowed their binding at the active binding site of TMPRSS2. This competitive inhibition of TMPRSS2 could help in the control of COVID-19 viral infection. The docking alignment of all ligands on TMPRSS2 is presented in Figure 7.

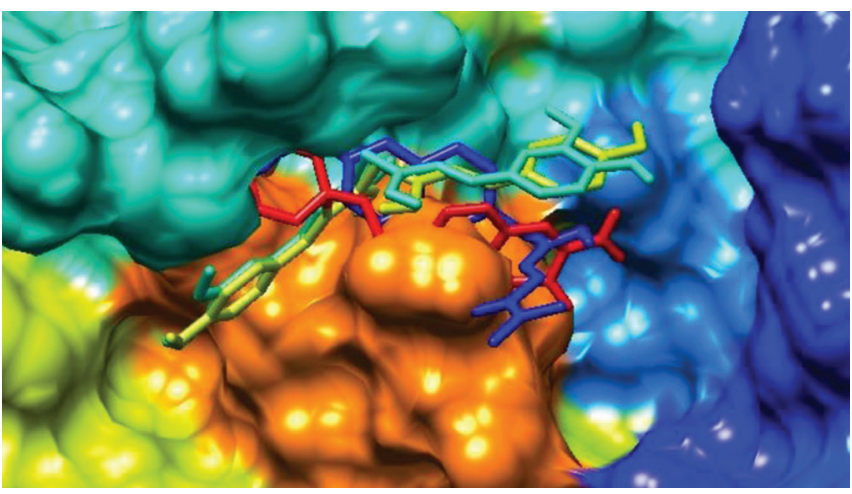

Figure 7. Docking alignment of all ligands on human TMPRSS2. Curcumin (yellow), folic acid (red), nafamostat (opal blue), and camostat (blue) docked on TMPRSS2 protein.

\section{Conclusion}

Based on the current molecular docking study, curcumin and nafamostat form four hydrophobic interactions and an H-bond with TMPRSS2. Nonetheless, folic acid and camostat form two hydrophobic interactions and three H-bonds with TMPRSS2. Asn-451 located in the hydrophobic cavity of TMPRSS2 interacts with all the four ligands through H-bonds. These interactions play an important role in stabilizing TMPRSS2ligand complexes. These in silico results suggest that curcumin and folic acid inhibit TMPRSS2 protein with potency similar to nafamostat and camostat. Hence, curcumin and folic acid are potential therapeutic candidates for the inhibition of SARS-CoV-2 and the treatment of COVID-19.

\section{Acknowledgments}

The authors would like to thank Dr. Thomas L. for sharing information which was published on the internet. R.G. is grateful to Professor Lester A. Mitscher (now deceased) for introducing to the computational docking studies at the earlier stages of drug discovery.

\section{Conflict of interest}

The authors declare that they have no conflicts of interest of any kind for this study.

\section{Author contributions}

R.G. conceived, designed, completed the experiments, and prepared the manuscript. A.V. and 
N.M. participated in technical discussion, created and arranged the graphics, and edited the manuscript.

\section{References}

[1] Nicola, M.; Alsafi, Z.; Sohrabi, C.; Kerwan, A.; Al-Jabir, A.; Iosifidis, C.; Agha, M.; Agha, R. The Socio-economic Implications of the Coronavirus Pandemic (COVID-19): A Review. Int. J. Surg., 2020, 78, 185-193.

[2] Hoffmann, M.; Kleine-Weber, H.; Schroeder, S.; Kruger, N.; Herrler, T.; Erichsen, S.; Scheirgens, T.S.; Herrler, G.; Wu, N.; Nitsche, A.; Muller, M.A.; Drosten, C.; Pohlmann, S. SARS-CoV-2 Cell Entry Depends on ACE2 and TMPRSS2 and is Blocked by Clinically Proven Protease Inhibitor. Cell, 2020, 181(2), 271-280.

[3] Li, X.; Ma, X. Acute Respiratory Failure in COVID-19: Is it "Typical” ARDS Critical. Care, 2020, 24, 198.

[4] Bosch, B.J.; van der Zee, R.; de Haan, C.A.; Rottier, P.J. The Corovavirus Spike Protein is a Class I Virus Fusion Protein: Structural and Functional Characterization of the Fusion Core Complex. J. Virol., 2003, 77(16), 8801-8811.

[5] Gierer, S.; Bertram, S.; Kaup, F.; Wrensch, F.; Heurich, A.; Kramer-Kuhl, A.; Welsch, K.; Winkler, M.; Meyer, B.; Drosten, C.; Dittmer, U.; von Hahn, T.; Simmons, G.; Hofmann, H.; Pohlmann, S. The Spike Protein of the Emerging Betacoronavirus EMC Uses a Novel Coronavirus Receptor for Entry, can be Activated by TMPRSS2, and is Targeted by Neutralizing Antibodies. J. Virol., 2013, 87(10), 5502-5511.

[6] Harbig, A.; Mernberger, M.; Bittel, L.; Pleschka, S.; Schughart, K.; Steinmetzer, T.; Stiewe, T.; Nist, A.; Bottcher-Friebertshauser, E. Transcriptome Profiling and Protease Inhibition Experiments Identify Proteases that Activate H3N2 Influenza A and Influenza B Viruses in Murine Airway. J. Biol. Chem., 2020, 295(33), 11388-11407.

[7] Shirato, K.; Kawase, M.; Matsuyama, S. Middle East Respiratory Syndrome Coronavirus Infection Mediated by the Transmembrane Serine Protease TMPRSS2. J. Virol., 2013, 87(23), 12552-12561.

[8] Hatesuer, B.; Bertram, S.; Mehnert, M.; Bahgat, M.M.; Nelson, P.S.; Pohlmann, S.; Schughart, K. Tmprss2 is Essential for Influenza H1N1 Virus Pathogenesis in Mice. PLoS Pathog., 2013, 9, e1003774.

[9] Sakai, K.; Ami, Y.; Tahara, M.; Kubota, T.; Anraku, M.; Abe, M.; Nakajima, N.; Sekizuka, T.; Shirato, K.; Suzaki, Y.; Ainai, A.; Nakatsu, Y.; Kanou, K.; Nakamura, K.; Suzuki, T.; Komase, K.; Nobusawa, E.; Maenaka, K.; Kuroda, M.; Hasegawa, H.; Kawaoka, Y.; Tashiro, M.; Takeda, M. The Host Protease TMPRSS2 Plays a Major Role in In Vivo Replication of Emerging H7N9 and Seasonal Influenza Viruses. J. Virol., 2014, 88(10), 5608-5616.

[10] Hondermarck, H.; Barlett, N.W.; Nurcombe, V. The Role of Growth Factor Receptors in Viral Infections: An Opportunity for Drug Repurposing against Emerging Viral Diseases such as COVID-19? FASEB Bioadv., 2020, 2, 296-303.

[11] The Impact of Camostat Mesilate on COVID-19 Infection (CAMOCO-19). Clinical Trails. NIH U.S. National Library of Medicine, 2020, NCT04321096, Available from: https://clinicaltrials. gov/ct2/show/NCT04321096. [Last accessed on 2020 Oct 14].

[12] Kawase, M.; Shirato, K.; Van der Hoek, L.; Taguchi, F.; Matsuyama, S. Simultaneous Treatment of Human Bronchial Epithelial Cells with Serine and Cysteine Protease Inhibitors Prevents Severe Acute Respiratory Syndrome Coronavirus Entry. J. Virol., 2012, 18(12), 6537-6545.

[13] Hoffmann, M.; Schroeder, S.; Kleine-Weber, H.; Muller, M.A.; Drosten, C.; Pohlmann, S. Nafamostat Mesylate Blocks Activation of SARS-CoV-2: New Treatment Option for COVID-19. Antimictob. Agents Chemother., 2020, 64(6), e00754-20.

[14] Mathew, D.; Hsu, W. Antiviral Potential of Curcumin. J. Funct. Foods, 2018, 40(1), 692-699.

[15] Manoharan, Y.; Haridas, V.; Vasanthakmar, K.C.; Muthu, S.; Thavoorullah, F.F.; Shetty, P. Curcumin: A Wonder Drug as Preventive Measure for COVID19 Management. Ind. J. Clin. Biochem., 2020, 35(3), 373-375.

Das, S.; Sarmah, S.; Lyndem, S.; Roy, A.S. An Investigation into the
[21] Bordoli, L.; Kiefer, F.; Arnold, K.; Benkert, P.; Battey, J.; Schwede, T. Protein Structure Homology Modeling Using SWISSMODEL Workspace. Nat. Protoc., 2008, 4, 1-13.

[22] Biasini, M.; Bienert, S.; Waterhouse, A.; Arnold, K.; Studer, G. Schmidt, T.; Kiefer, F. SWISS-MODEL: Modeling Protein Tertiary and Quaternary Structure Using Evolutionary Information. Nucleic Acids Res., 2014, 42(W1), 252-258.

[23] Read, R.J.; Adams, P.D.; Arendall, W.B. $3^{\text {rd }}$; Brunger, A.T.; Emsley, P.; Joosten, R.P.; Kleywegt, G.J.; Krissinel, E.B.; Lutteke, T.; Otwinowski, Z.; Perrakis, A.; Richardson, J.S.; Sheffler, W.H.; Smith, J.L.; Tickle, I.J.; Vriend, G.; Zwart, P.H. A New Generation of Crystallographic Validation Tools for the Protein Data Bank. Structure, 2011, 19(10), 1395-1412.

[24] Savarino, A. In Silico Docking of HIV-1 Integrase Inhibitors Reveals a Novel Drug Type Acting on an Protein/DNA Reaction Intermediate. Retrovirology, 2007, 4(21), 1-15.

[25] Dubey, K.; Dubey, R.; Gupta, R.G.A. In-Silico Reverse Docking Studies for the Identification of Potential of Betanin on Some Proteins Involved in Diabetes and its Complications. J. Drug Deliv. Ther., 2019, 9, 72-74.

[26] Madhuri, M.; Rao, P.C.; Avupati, V. In Silico Protein-ligand Docking Studies on Thiazolidinediones as Potential Anticancer Agents. Int. J. Comput. Appl., 2014, 95, 13-16.

[27] Heble, N.K.; Mavillapalli, R.C.; Selvaraj, R.; Jeyabalan, S. Molecular Docking Studies of Phytoconstituents Identified I Crocus sativus, Curcuma longa, Cassia occidentalis and Moringa oleifera on Thymidylate Synthase an Protein Target for AntiCancer Activity. J. Appl. Pharm. Sci., 2016, 6, 131-135.

[28] Mavillapalli, R.C.; Jayabalan, S.; Muthusamy, S. Molecular Docking Studies of Phytoconstituents Identified in Cinnamomum verum and Coriandrum sativum on HMG COA Reductase a Protein Target for Antihyperlipidemic Activity. Int. J. Pharm. Sci. Res., 2017, 8, 4172-4179.

[29] Elmezayen, A.D.; Al-Obaidi, A.; Sabin, A.T.; Yelekci, K. Drug Repurposing of Coronavirus (OVID-19): In Silico Screening of Known Drugs against 3CL Hydrolase and Protease Proteins. J. Biomol. Struct. Dyn., 2020, 26, 1-13.

[30] Chen, D.; Oezguen, N.; Urvil, P.; Ferguson, C.; Dann, S.M.; Savidge, T.C. Regulation of Protein-ligand Binding Affinity by Hrogen Bond Pairing. Sci. Adv. 2016, 2, e1501240.

[31] Donaldson, S.H.; Hirsh, A.; Li, D.C.; Holloway, G.; Chao, J.; Boucher, R.C.; Gabriel, S.E. Regulation of the Epithelial Sodium Channel by Serine Proteases in Human Airways. J. Biol. Chem., 2002, 277, 8338-8345.

[32] Kim, T.S.; Heinlein, C.; Hackman, R.C.; Nelson, P.S. Phenotypic Analysis of Mice Lacking the Tmprss2-encoded Protease. Mol. Cell Biol., 2006, 26, 965-975.

[33] National Library of Medicine. The Impact of Camostat Mesilate on COVID-19 Infection (CamoCO-19). Clinical Trails. NIH U.S. National Library of Medicine. NCT04321096. Available from: https://www.clinicaltrials.gov/ct2/show/NCT04321096.

[34] Uno, Y. Camostat Mesilate Therapy for COVID-19. Emerg. Med. Int., 2020, 29, 1-2.

[35] Braun, E.; Saulter, D. Furin-mediated Protein Processing in Infectious Diseases and Cancer. Clin. Transl. Immunol., 2019, 8(8), e1073. 